\title{
DIFERENCIAÇÃO DOS CANAIS LOGÍSTICOS EMPRESARIAIS: UM ENFOQUE BIBLIOGRÁFICO
}

\author{
Alvaro Costa Jardim Neto, Jean Carlos Silva Santos, Valdecir Cahoni Rodrigues \\ Universidade do Oeste Paulista - UNOESTE. Curso de Administração, Presidente Prudente - SP. E-mail: \\ alvaro@unoeste.br
}

\begin{abstract}
RESUMO
A temática sustentabilidade tem tomado destaque nas discussões empresariais e a logística direta e reversa entram como diferenciais no intuito de economizar, melhorar os processos produtivos e preservar o meio ambiente. A logística direta liga a empresa ao consumidor final através produtos e serviços, já a logística reversa tem por responsabilidade reaproveitar ou destinar corretamente após a utilização final dos mesmos e se dividem em duas áreas: logística pós venda e logística de pós-consumo cujo se responsabiliza pelo descarte e reciclagem de produtos. Assim, através de uma metodologia de pesquisa com enfoque na natureza exploratória e bibliográfica, o estudo buscou esclarecer os conceitos e a importância da logística dentro da esfera empresarial dando enfoque na diferenciação de ambas. Desta forma pode-se concluir que as relações entre os tipos logísticos apresentados devem ser esclarecidas para as organizações com o intuito de melhor adotar tais mecanismos de forma estratégica.
\end{abstract}

PALAVRAS-CHAVE: logística empresarial, pós-venda, pós consumo, suprimentos, produtos.

\section{DIFFERENTIATION OF LOGISTICS BUSINESS CHANNELS: A BIBLIOGRAPHICAL FOCUS}

\begin{abstract}
The sustainability theme has taken prominence in business discussions and direct and reverse logistics enter as differentials in order to save money, improve the production processes and preserve the environment. Direct logistics connects the company to final consumers through products and services, the reverse logistics has the responsibility to reuse or allocate properly after the same end use and are divided into two areas: after sales logistics and post-consumer logistics whose responsible for the disposal and recycling of products. Thus, through a research methodology with a focus on nature and the bibliographical study exploratory sought to clarify the concepts and importance of logistics within the business sphere giving focus on differentiation of both. Thus it can be concluded that relations between kinds of logistics presented should be clarified for organizations aiming to better adopt such mechanisms strategically.
\end{abstract}

KEYWORDS: business logistics, after sales, consumption, supplies, powders products. 
INTRODUÇÃO E OBJETIVO

A terminologia logística empresarial, embora de utilização rotineira, sempre foi aplicada as organizações, pois consiste nas ações da empresa que estão relacionadas com as atividades de suprimento suprimentos, manutenção, transporte, estocagem, armazenamento das mercadorias e distribuição de materiais, serviços ou produtos diversos. Tem em seu conjunto os mais variados processos que a integram como: planejamento, operação e controle do fluxo de materiais, mercadorias, serviços e informações da empresa, integrando e racionalizando as funções sistêmicas, desde a produção até a entrega, de forma que adquira vantagens competitivas em suas redes de suprimentos e por fim também na satisfação dos clientes.

Com o passar dos anos as empresas deram início a um processo de integração da cultura logística e a utilizaram como forma de desenvolvimento e redução de custos, coordenando de forma que a sua otimização seja geral e realmente aplicada, em busca do melhor resultado em cima do objetivo empresarial. Desta forma, a logística tem o poder de agregar valor para os produtos e serviços para os clientes, sendo primordial o objetivo de satisfazer o cliente aliando às estratégicas logísticas as ações de Marketing.

O objetivo do presente artigo é demonstrar as diversas áreas em que a logística possui poder de operação a fim de desmistificar o seu poder de atuação dentro das organizações, com enfoque na logística reversa dentro dos canais de distribuição baseando-se nas políticas de pósvenda e pós-consumo. Este estudo destaca-se no norteamento para a diferenciação das mesmas e a sua capacidade de adequação as estratégias, garantindo a sustentabilidade da organização. Para isso foi realizada uma pesquisa exploratória, com caráter interpretativo e natureza qualitativa.

\section{RESULTADOS}

Nos últimos anos, a logística apresenta uma crescente evolução constante, considerada hoje uma parte integrante de elementos-chave na formação da estratégia competitiva para diferenciais das empresas, onde cada vez mais o cenário mundial está propicio para o setor logístico e este está angariando grande importância nas organizações, tornando-se elemento critico e dessa forma exigindo maior atenção dos administradores em relação ao desenvolvimento de suas atividades.

Christopher (1999, p. 2) trata a logística através do seguinte conceito:

A Logística é o processo de gerenciar estrategicamente a aquisição, movimentação e armazenagem de materiais, peças e produtos acabados (e os fluxos de informações correlatas) através da organização e seus canais de 
marketing de modo a poder maximizar as lucratividades presentes e futuras através do atendimento dos pedidos a baixo custo.

O estudo da logística é um campo relativamente novo, porém a sua utilização vem sendo desenvolvida há muito tempo pelo ser humano. Por envolver operações complexas e manter suas particularidades devido a geografia, gastos e seus custos, seu processo sempre está em constante renovação e a "implementação das melhores práticas logísticas tornou-se uma das áreas mais desafiadoras e interessantes da administração nos setores privado e público", (BOWERSOX; CLOSS, 2009 p. 19).

De acordo com Lalonde (1969, apud POZO, 2002, p. 15), a palavra logística deriva do grego e significa "a arte de calcular", porem existem várias versões para a origem do termo, dentre tantas se destaca suas origens da palavra francesa "loger" que significa acomodar, ao mesmo tempo em que também citam a origem deste termo na língua grega através da palavra "logos" que significa "a arte de calcular" ou em alguns casos também pode significar "manutenção dos detalhes de uma operação."

Inicialmente a logística teve suas origens ligadas à arte da guerra, a área militar, onde sua utilização era dada como diferencial de poderio, não baseada na força bélica, mas sim como coeficiente de razão nos confrontos onde esta arcava com a responsabilidade de deslocar os exércitos, aquisições para suprimento garantindo que os recursos estariam no local certo e na hora certa. A partir desta utilização veio a tona o reconhecimento do termo logística que proporcionou ao longo do tempo que seu conceito fosse ampliado e a sua aplicação no meio empresarial tornou-se essencial.

Nos anos 70, diversos fatores fizeram com que a economia dos EUA fosse afetada, de certo que a economia mundial entrou no mesmo efeito logo em seguida e as atividades logísticas sofreram muito mais que as outras áreas das organizações em geral, pois seus custos sofreram forte mudança em suas operações, fazendo com que as discussões sobre estes assuntos se tornassem cada vez mais relevantes nos setores estratégicos de cada empresa.

Razzolini (2008) afirma que a partir dos anos 80 o foco no mercado e nos clientes retoma com maior ênfase marca o inicio da cadeia de suprimentos fomentada pela globalização e os avanços nos sistemas da tecnologia da informação (TI) e seu desenvolvimento foi revolucionário nesta década. Em seguida, adentrando a década de 90 até atualmente, a logística somente progrediu e proporcionou uma visão cada vez mais estratégica, e com a sua utilização passou a ser elemento diferenciador levando ao surgimento do conceito de Supply Chain Management (SCM), Enterprise Resource Planning (ERP), Customer Relationship Management (CRM), Warehouse 
Management System (WMS), Eletronic Data Interchange (EDI) e contribuindo para o desenvolvimento da logística integrada. Tratando do se de Brasil, o fator de crescimento para do setor foi a explosão do mercado internacional e a estabilização produzida pela moeda do real, colaborando para a estabilização econômica e alavancagem do setor logístico.

\section{DISCUSSÃO}

\section{Logística Direta}

Tratando da trajetória de desenvolvimento da logística ao longo das décadas e verificando que cada vez mais o mercado exige flexibilidade e agilidade por parte das empresas, a integração dos processos logísticos se tornou cada vez mais real, possibilitando atender melhor a parte do mercado ao qual atuam, pois esta transformação não foi obtida por acaso, mas sim por exigência própria do mercado.

Uma empresa com sistema logístico integrado e organizado torna-se destaque no sistema econômico desta forma valorizando o capital da empresa gerindo os custos e mantendo o capital próprio, abrangendo não somente o cenário regional, mas também um comercio mais amplo e entre os estados e países diversos.

Neste contexto, logística é entendida como o processo de planejar, organizar, implementar e controlar de forma eficiente, com um custo adequado a movimentação do fluxo e a armazenagem das matérias primas, o estoque, aquisição de produtos e materiais durante o processo de produção e os produtos a serem terminados, juntamente com as informações a cerca dessas atividades, como a estratégia adotada antes de dar inicio a produção, no decorrer e após a sua produção, sendo vinculados a logística de consumo e pós consumo, sendo tudo de forma eficaz de maneira que possa maximizar os lucros e reduzir os custos.

Com o conceito de logística se expandindo além dos limites da empresa, envolvendo também os integrantes da cadeia de suprimentos, o foco sempre será em valorizar o cliente atendendo as suas necessidades com ágil tempo de resposta desde a recepção do pedido até a entrega efetiva do produto, sempre sendo flexível ao tamanho do lote, surgindo então o conceito de gerenciamento da cadeia de suprimentos.

Os procedimentos logísticos de uma organização, sendo bem organizados e planejados destacam-se como forma de diferenciação na competição estratégica agindo como forma de obtenção de vantagens competitivas diferenciadas que vão além das qualidades inseridas no produto ou serviço prestado, sendo que o intuito é alcança-las a um longo prazo. 
Em seus estudos Ballou (2001, p. 39) destaca que uma estratégica logística bem estruturada atinge os seguintes objetivos:

- Redução de custo: onde a estratégia se baseia na direção ao qual o mínimo de custos variáveis deve ser alcançado referente a movimentação e estocagem de materiais, sendo que é necessário analisar os meios alternativos, com base em escolha entre diferentes locais de armazenagem e/ou meios de transporte, trazendo então maximização dos lucros;

- Redução do capital: estratégia traçada para minimizar o investimento no setor logístico e maximizar o retorno nos investimentos feitos. Transportar com canal direto ao cliente, selecionar meios de suprimento just-in-time, evitar armazenagem ou estoque e terceirizar serviços logísticos são algumas das atitudes viáveis para essa estratégia funcionar;

- Melhorias no serviço: são estratégias que usam do reconhecimento de que as receitas utilizadas estarão ligadas ao serviço que será oferecido, apesar de que os custos tentem a crescer de forma rápida com níveis de serviços elevados aos clientes.

O conjunto de necessidades do consumidor a ser alcançado é o que define a estratégia competitiva da empresa a ser satisfeita através dos seus produtos e serviços, sendo que uma vez adotada a estratégia o objetivo é alcança-la.

\section{Logistica Reversa}

Logística Reversa é um termo bastante genérico. Em seu sentido mais amplo, significa todas as operações relacionadas com a reutilização de produtos e materiais. Logística reversa se refere a todas as atividades logísticas de coletar, desmontar e processar produtos e/ou materiais e peças usados a fim de assegurar uma recuperação sustentável.

Segundo Dornier et. al. (2000, p 40):

No início, os investimentos em logística focou-se principalmente nos fluxos das empresas para os mercados. Preocupações crescentes para proteger o ambiente e conservar recursos criaram a necessidade de gerenciar fluxos reversos - dos mercados de volta à empresa. A ênfase aqui é na reutilização, reembalagem, renovação ou disponibilização de artigos usados.

Como parte integrante da logística empresarial a logística reversa tem por objetivo construir um correto planejamento, dar inicio as operações e manter o controle do fluxo, de acordo com as informações logísticas correspondentes, ao retorno dos bens de pós-venda e de pós - consumo ao ciclo de negócios ou ao ciclo produtivo, através dos centros de distribuição diversos, agregando valor tais como: econômico, ecológico, legal, logístico, de imagem corporativa, entre outros (LEITE, 2006). 
Dentre os principais motivos para a inserção da logística reversa na estratégia empresarial podemos destacar algumas como:

- Leis ambientais que estimulam as empresas a utilizar ou dar o fim correto a estes resíduos;

- Rede de ganhos econômicos devido ao uso materiais que retomam ao processo de produção dê produtos que retornam ao processo de produção, em contraposição aos custos altos após o descarte do lixo;

- Conscientização socioambiental dos consumidores.

As empresas tendem a buscar renovação em suas estratégias dentro da logística empresarial, e uma delas é a utilização de embalagens e produtos retornáveis, que grandes empresas conseguem um considerável retorno, proporcionando a reutilização de partes do produto no processo de produção, agregando novos valores a organização e proporcionando uma justificativa para os investimentos realizados.

\section{Logística Reversa de Pós-venda}

O conceito de pós-venda dentro da logística reversa se caracteriza quando existe reutilização, a revenda de produtos de segunda linha e a reciclagem de produtos que são devolvidos pelo cliente dentro de qualquer fase da cadeia de distribuição ocasionado por erros na fase comercial, perca da validade do bem ou defeitos, e entregues ao varejista, atacadista ou ao produtor.

De acordo com Leite (2003), logística reversa de pós-venda consiste no setor ao qual planeja, opera e controla os fluxos físicos e de informações logísticas relacionados a pós-venda, sem uso ou com pouco uso, que por motivos diversos retornaram uma determinada parte da distribuição direta onde fluem estes produtos.

Para conquistar vantagens competitivas através do pós-venda é necessário que o mesmo seja bem gerenciado e que a estrutura da organização seja clara e concisa, assim agregando valor na diferenciação do atendimento ao cliente, possibilitando assim sua fidelização. Empresas lideres de mercado procuram assumir esse papel em sua estratégia de mercado, focando nesta parceria entre cliente e empresa, reduzindo impactos ambientais e uma boa imagem no marketing empresarial. 
Logística Reversa de Pós-consumo

Bens de produtos relacionados a pós consumo são aqueles que já encerram sua vida e estão preparados para serem enviados a destinos finais de destinos comuns, ou retornar a movimentação comum do ciclo produtivo, desmanche, reciclagem e reuso em uma extensão de sua vida útil.

Na opinião de Leite (2003, p. 83) “A logística reversa de pós-consumo contrariamente a logística reversa de pós-venda, no qual os fluxos reversos se processam por meio da parte da cadeia de distribuição direta, possui uma cadeia própria de canal formada por empresas especializadas por suas diversas etapas reversas, que formar o "Reverse Supply Chain".

Existem variados caminhos para recuperação e de agregação de valor econômico e ambiental aos bens de pós-consumo, sendo eles: reuso, reciclagem de materiais e incineração. Assim, Leite (2003) declara que o sistema de reciclagem agrega valor econômico, ecológico e logístico aos bens de pós-consumo, criando condições para que o material seja reintegrado ao ciclo produtivo e substituindo as matérias-primas novas, gerando uma economia reversa; o sistema de reuso agrega valor de reutilização ao bem de pós-consumo; e o sistema de incineração agrega valor econômico, pela transformação dos resíduos em energia elétrica.

\section{CONCLUSÃO}

A logística ao ser corretamente aplicado permite desenvolver estratégias para que possa reduzir o máximo de custos e aumentar o nível de serviço ofertado ao cliente, e a utilização dessas condições em conjunto proporciona uma pura vantagem para combater com a concorrência e obter benefícios sobre a utilização.

Verificamos essa situação de vantagem quando se analisa os segmentos mais competitivos do mercado, assim como o automobilístico, o varejo utiliza todo o seu foco na estratégia de logística. Portanto vale analisar minuciosamente os processos ao qual interferem na cadeia logística, assim como os seus canais de suprimentos, ao qual influenciam no objetivo final da organização.

Este trabalho teve o intuito de mostrar o desenvolvimento da logística empresarial, fundamentando os conceitos de logística reversa e seus agregados a fim de demonstrar o valor agregado através da inclusão da logística reversa como valorização do capital da empresa e como parte de conscientização ambiental.

Desta maneira, tomando por base o referencial teórico estudado, pode-se dizer que a utilização da ferramenta logística proporciona diferencial competitivo entre as empresas que se 
adequam a ela e a gerenciam de forma correta, potencializando também o seu capital e podendo manter o sistema sustentável ativo por meio da reutilização dos seus resíduos ou encaminhamento correto dos mesmos.

\section{REFERÊNCIAS}

BALLOU, R. H. Logística Empresarial: transportes, administração de materiais e distribuição física. São Paulo: Atlas, 1993.

BOWERSOX; D. J.; CLOSS, D. J.; Logistica empresarial: O processo de integração da cadeia de suprimento. Tradução Equipe do Centro de Estudos em Logistica, Adalberto Ferreira das Neves. 1.ed. - 7. Reimpre. São Paulo: Atlas, 2009.

CHRISTOPHER, M. A. Logística do Marketing: otimizando processos para aproximar fornecedores e clientes. 4. ed. São Paulo: Futura, 1999.

FLEURY, P. F.; WANK, P.; FIGUEIREDO, K. F. Logística Empresarial: a perspectiva brasileira. São Paulo: Atlas, 2000

LACERDA, L. Logística Reversa - Uma Visão sobre os Conceitos Básicos e as Práticas Operacionais. Centro de Estudos em Logística, COPPEAD, Universidade Federal do Rio de Janeiro, Rio de Janeiro, 2002. Disponível em <http://www.ecodesenvolvimento.org /biblioteca/artigos/logistica-reversauma-visao-sobre-os-conceitos> Acesso em: 17 agos de 2014.

LEITE, P. R. Logística reversa: meio ambiente e competitividade. São Paulo: Pearson Prentice Hall, 2003.

. Logística reversa: meio ambiente e competitividade. $2^{\circ}$ ed. São Paulo: Pearson Prentice Hall, 2006.

POZO, H. Administração de recursos materiais e patrimoniais: uma abordagem logística. 2. ed. São Paulo: Atlas, 2002.

RAZZOLINI Fo, E. Logística: evolução na administração - desempenho e flexibilidade. Curitiba: Juruá, 2008. 